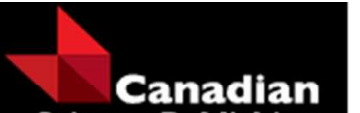

Science Publishing

Canadian Journal of Physiology and Pharmacology

Revue canadienne de physiologie et pharmacologie

\title{
The Protective Effect of Vildagliptin in Chronic Experimental Cyclosporine A-Induced Hepatotoxicity
}

\begin{tabular}{|r|l|}
\hline Journal: & Canadian Journal of Physiology and Pharmacology \\
\hline Manuscript ID & cjpp-2015-0336.R1 \\
\hline Manuscript Type: & Article \\
\hline Complete List of Authors: & $\begin{array}{l}\text { El-Sherbeeny, Nagla; Faculty of Medicine- Suez Canal university, Clinical } \\
\text { Pharmacology; Taibah University- Faculty of Pharmacy, Pharmacology } \\
\text { Nader, Manar; Faculty of Pharmacy- Mansoura university, Pharmacology } \\
\text { and toxicology }\end{array}$ \\
\hline Keyword: & Vildagliptin, cyclosporine, oxidative stress, inflammation, apoptosis \\
\hline \multicolumn{2}{|c}{} \\
\hline
\end{tabular}

\section{SCHOLARONE ${ }^{m}$}

Manuscripts 


\section{The Protective Effect of Vildagliptin in Chronic Experimental Cyclosporine A-Induced Hepatotoxicity}

Nagla A. El-Sherbeeny ${ }^{a^{*}}$, Manar A Nader ${ }^{b}$

${ }^{a}$ Lecturer of Pharmacology, Faculty of Medicine, Suez canal University, Egypt and College of Pharmacy, Taibah University, El-Madinah El-Munawarah, Saudi Arabia

${ }^{\mathrm{b}}$ Assistant Professor of Pharmacology and Toxicology, College of Pharmacy, Taibah University, El-Madinah El-Munawarah, Saudi Arabia and Faculty of Pharmacy, Mansoura University, Egypt

*Corresponding author:

Nagla A. El-Sherbeeny, MD, PhD

Lecturer of Pharmacology, Faculty of Medicine, Suez canal University, Egypt and College of Pharmacy, Taibah University, El-Madinah El-Munawarah, Saudi Arabia Tel: 00966508218725

Email: n_elsherbeeny@hotmail.com 


\begin{abstract}
The study examined the effect of dipeptidyl peptidase-4 (DPP-4) inhibitor, vildagliptin in cyclosporine (CsA)-induced hepatotoxicity. Rats were divided into 4 groups treated for 28 days: control (vehicle), vildagliptin (10 mg/kg, orally), CsA( $20 \mathrm{mg} / \mathrm{kg}, \mathrm{SC})$ and CsA-vildagliptin group. Liver function was assessed by measuring serum levels of Aspartate aminotransferase (AST), alanine aminotransferase (ALT), gamma glutamyltransferase $(\gamma \mathrm{GT})$, lactate dehydrogenase (LDH), albumin, and histopathological changes of liver were examined. Oxidative stress markers were evaluated. Assessment of nuclear factor-kappa B (NF- $\mathrm{B})$ activity in hepatic nuclear extract, serum DPP-4 and expression of Bax and Bcl2 using were also done. CsA-induced hepatotoxicity was evidenced by increase in serum levels of AST, ALT and $\gamma$ GT; a decrease in serum albumin and a significant alteration in hepatic architecture. Also, significant increase in thiobarbituricacid reactive substance (TBARS) and decrease in superoxide dismutase (SOD), catalase (CAT), glutathione peroxidase (GPx) and glutathione (GSH) levels, increased expression Bax proteins with deceased expression of $\mathrm{Bcl} 2$, increased hepatic activity of NF- $\kappa \mathrm{B}$, and serum DPP-4 level were observed upon CsA treatment. Vildagliptin significantly improved all altered parameters induced by CsA administration. Vildagliptin has the potential to protect the liver against CsA-induced hepatotoxicity by reducing oxidative stress, DPP-4 activity, apoptosis and inflammation.
\end{abstract}

Key words: Vildagliptin, cyclosporine, oxidative stress, inflammation, apoptosis. 


\section{Introduction}

CsA is an immunosuppressive agent that is commonly used in the treatment of many autoimmune diseases and after organ transplantations (Kwak and Mun 2000; Rezzani et al. 2001). However, its use is limited due to several side effects, including nephrotoxicity, cardiotoxicity, hypertension and hepatotoxicity. Impairments in liver architecture have been reported in rats given CsA for 2-13 weeks (Rezzani 2004; Josephine et al. 2008; Lee 2010). Cholestasis, hyper-bilirubinemia, hypoproteinemia, increased alkaline phosphatase and transaminases activities, bile salts in the blood, inhibition of protein synthesis and disturbed lipid secretion in both human and experimental animals were found to characterize CsA-induced hepatotoxicity (McCashland et al. 1994; Rezzani 2004). Additionally, alterations in bile formation, the capacity of the liver to excrete organic anions and xenobiotics and changes in the hepatic content of glutathione (GSH) are also prominent in CsA provoked liver damage (Morán 1998). Several mechanisms are involved in CsA-induced hepatotoxicity including reactive oxygen species (ROS) production, oxidative stress and depletion of the hepatic antioxidant system (Rezzani et al. 2005).

Dipeptidyl peptidase-4 (DPP-4) is a membrane-associated peptidase known as CD26. Vildagliptin is a DPP-4 inhibitor which increases plasma level of active glucagon-like peptide-1 (GLP-1), improves glucose-dependent insulin secretion, $\beta$-cell function, improves insulin sensitivity, reduces inappropriate glucagon secretion, and reduces fasting and postprandial glucose (Barnett 2006). DPP-4 has widespread organ distribution throughout the body and exerts pleiotropic effects via its peptidase activity. DPP-4 is involved in immune stimulation, binding to and degradation of extracellular matrix, resistance to anti-cancer agents, and lipid accumulation (Itou et al. 2013). Tumor necrosis factor- $\alpha$ (TNF- $\alpha$ ), interferons, retinoic acid, high insulin levels, glucose, and hypoxia are some of the factors that influence the production and release of DPP4; however, the mechanisms of action involved remain unknown. DPP4 activity levels in the serum have been shown to increase under conditions such as nonalcoholic fatty liver disease, rheumatoid arthritis, and inflammatory bowel disease (Das et al. 2014). Also, DPP-4 is highly expressed in the liver, and recent data suggested that DPP-4 is involved in the development of various chronic liver diseases such as hepatitis $\mathrm{C}$ virus infection, non-alcoholic fatty liver disease, and hepatocellular carcinoma. DPP-4 expression has similar lobular 
heterogeneity seen in the expression of cytochrome p450, gamma-glutamyl -transpeptidase (GGT), and glutamine synthetase (Mentzel et al. 1996; Gorrell et al. 2001). This heterogeneous lobular distribution suggests that DPP-4 may be involved in the regulation of hepatic metabolism. Furthermore, DPP-4 occurs in hepatic stem cells and plays a crucial role in hepatic regeneration (Itou et al. 2013). Therefore, the present study was undertaken to assess the possible beneficial effects of vildagliptin in CsA-induced hepatotoxicity in rats.

\section{Materials and Methods}

\section{Animals:}

Thirty-two male Sprague-Dawley rats (purchased from urology and nephrology center), weighing between 200-250 g were housed for 28 days in a well-ventilated room with a 12:12hour light/dark cycle and were allowed access to water ad libitum and fed a normal rat chow. The experimental protocol conducted in the study complies with the ethical guidelines and the principals of care, use and handling of experimental animals adopted by "The research Ethics Committee", Faculty of Pharmacy, Mansoura University, Egypt which is in accordance with "Principles of Laboratory Animals Care" (NIH publication No. 85-23, revised 1985).

\section{Experimental design:}

Rats were randomly divided into 4 groups with 8 rats each and were treated as follows: group 1 (control group), rats received $2 \mathrm{ml} / \mathrm{kg}$ sunflower oil, refined bleached deodorized (RBD) (CsA vehicle) by SC injection and $2 \mathrm{ml} / \mathrm{kg} 0.5 \%$ carboxymethyl cellulose(vilagliptin vehicle) by oral gavage daily for 28 days; group 2 (vildagliptin group) animals treated with daily oral vildagliptin (10mg/kg, Novartis Pharma AG, Basil ,Switzerland); group 3 (CsA group) rats received a daily dose of $20 \mathrm{mg} / \mathrm{kg}$ of CsA (Novartis Pharma AG, Basil ,Switzerland) by SC injection, delivered by dilution in $0.1 \mathrm{ml} / \mathrm{kg}$ of sunflower oil; group 4 (CsA-vildagliptin) rats given daily doses of vildagliptin and CsA for 28 days. This treatment schedule and dose level were chosen based on the results obtained in pilot experiments using lower doses of vildagliptin ( 1 and $5 \mathrm{mg} / \mathrm{kg}$ ), which failed to decrease the elevated serum ALT and AST levels (data not shown). 
At the end of day 28 of the experiment, each rat was anesthetized by thiopental sodium solution at a dose of $30 \mathrm{mg} / \mathrm{kg}$ IP (Wixson et al. 1987). Blood was collected from the retro-orbital sinus and serum was separated by centrifugation at $1000 \mathrm{rpm}$ for $20 \mathrm{~min}$ then used for analyzing the biochemical parameters.

The liver was rapidly excised, a part was used for measurement of biological markers after homogenization and the other was used for histopathological examination.

\section{Preparation of liver homogenate:}

Excised livers were rinsed with ice-cold isotonic saline (0.9\%), weighed and then homogenized immediately in ice-cold $1.15 \% \mathrm{KCl}$ solution to give a $10 \%(\mathrm{w} / \mathrm{v})$ homogenate. Homogenates were centrifuged at $10,000 \mathrm{~g}$ for $20 \mathrm{~min}$ at $4^{\circ} \mathrm{C}$ to obtain the supernatant fractions which were used for determination of oxidative stress parameters and $\mathrm{Bax}$ and $\mathrm{Bcl} 2$ expression.

\section{Assessment of hepatic oxidative markers:}

Enzymatic antioxidants were determined in liver homogenates by estimating SOD, CAT and GPx activity; non-enzymatic antioxidants by GSH and lipid peroxidation by measuring TBARS levels using commercially available kits (from Bio-diagnostic Company, Giza, Egypt).

\section{Assessment of Biochemical assays}

Determination of serum levels of AST, ALT, $\gamma \mathrm{GT}$, LDH and albumin were done using commercially available kits (Biomerieux, Marcy-l'Etoile, France) according to manufacturer's instructions.

\section{Hepatic nuclear factor-kappa B (NF-кB) activation:}

The transcription factor NF-kB activation was measured according to manufacturer's instructions using a commercially available enzyme linked immunosorbent assay (ELISA) kit (Trans-AM ${ }^{\text {TM }}$ NF-kB p65 Transcription Factor Assay Kit, Active Motif, CA). Nuclear protein extract was obtained using Nuclear Extract Kit (Active Motif) according to manufacturer's instruction. Subsequently, $15 \mu \mathrm{g}$ nuclear protein extract was used to assay for NF-kB activation. Values were represented as OD $450 \mathrm{~nm}$.

\section{Assessment of DPP-4 level:}

The amount of DPP-4 level in serum was measured using ELISA kit (antibodies-online Inc., Atlanta, USA) according to the manufacturer's directions. 


\section{Assessment of Bax and Bcl-2 in hepatic tissue:}

Rat Bax ELISA kit and Rat Bcl-2 ELISA kit (antibodies-online Inc., Atlanta, USA) were used to evaluate the expression of $\mathrm{Bax}$ and $\mathrm{Bcl}-2$ proteins in the rat liver homogenates according to manufacturer instructions. The absorbance was read at $450 \mathrm{~nm}$.

\section{Histopathology of Liver tissue:}

Liver tissues were embedded in paraffin, and $4-5 \mu \mathrm{m}$ thick sections were stained with hematoxylin and eosin ( $\mathrm{H}$ and $\mathrm{E}$ ). The tissues were examined under a light microscope by histologists blinded to the treatment groups.

\section{Statistical analysis}

Data are expressed as mean \pm standard deviation (SD). Statistical analysis was carried out by one-way analysis of variance (ANOVA) followed by post hoc Tukey-Kramer multiple comparisons test. Statistical calculations were carried out using Instat-2 computer program (GraphPad Software Inc. V2.04, San Diego, CA, USA).

\section{Results:}

\section{Effect of vidagliptin on CsA-induced hepatotoxicity:}

As shown in (table 1), structural damage of the liver after treatment with CsA is evidenced by a significant elevation of ALT, AST, $\gamma \mathrm{GT}$ and LDH and a significant decrease of serum albumin levels as compared to the control. Vidagliptin treatment significantly improved all measured liver function parameters as compared to CsA.

\section{Effect of vildagliptin on CsA induced-hepatic pathological changes:}

Livers from normal rats administered vehicle or vildagliptin showed normal hepatic structure. Upon treatment with CsA, liver changes were evident including enlarged hepatocytes, numerous vacuoles, inflammatory cell infiltrate and dilated sinusoids with congestion. Rats that received both CsA and vildagliptin showed apparently less marked damage in liver tissue than that of liver tissue from CsA-treated rats (figure 1). 


\section{Effect of vildagliptin on CsA-induced oxidative stress:}

CsA caused significant elevation of hepatic oxidative stress as compared to control. This is evident by high levels of TBARS, a marker of increased lipid peroxidation. Also, CsA treatment as compared to control caused significant reduction of hepatic enzymatic antioxidant (SOD, CAT and GPx) activity and non-enzymatic antioxidants (GSH) as shown in (table 2). Administration of vildagliptin with CsA to rats significantly attenuated CsA-induced oxidative stress. Vildagliptin caused significant reduction in TBARS, elevation in SOD, CAT and GPX activities and restored GSH levels as compared to CsA-treated group (table 2).

\section{Effect of vildagliptin on serum DPP-4 level:}

Serum DPP-4 level was significantly increased by CsA administration indicating the high activity of DPP-4 enzyme compared to control non-treated rats. Upon vildagliptin concomitant treatment with CsA, vildagliptin was able to significantly reduce DPP-4 level to the normal value compared to CsA-treated group (table1).

\section{Effect of vildagliptin on hepatic NF-кB (p65) expression:}

Hepatic nuclear extract analysis for the transcription factor, NF- $\kappa \mathrm{B}$ activity showed significant increase in NF- $\kappa \mathrm{B}$ activity in CsA-treated rats compared to control rats which were significantly reduced upon vildagliptin treatment (table 3 ).

\section{Effect of vildagliptin on hepatic Bax and Bcl2 level:}

Increased apoptosis by CsA was evident by the increase in proapoptotic protein Bax with significant decrease of the anti-apoptotic protein Bcl2. Vildagliptin ameliorated CsA-induced apoptosis as marked by a significant decreased in the level of Bax protein and increased that of $\mathrm{Bcl} 2$ (table 4).

\section{Discussion}

The current study demonstrated the hepatotoxic effect of CsA when administered to rats for four weeks. Rats treated with CsA showed significant elevation of hepatic marker enzymes, AST, ALT, $\gamma \mathrm{GT}$ and LDH, and a significant decrease in albumin level as compared to control. These changes indicate damage of the structural integrity of the liver which was confirmed by the histopathological changes of the liver in CsA treated rats that revealed enlarged hepatocytes, 
numerous vacuoles, inflammatory cell infiltrate, and dilated sinusoids with congestionas compared to control. Vildagliptin ameliorated significantly the elevation of hepatic enzymes and the pathological changes of hepatic architecture induced by CsA.

ROS such as hydroxyl radicals, superoxide anions, and hydrogen peroxide are normally generated in the liver but this is counteracted by a detoxification system of endogenous antioxidants such as GSH, SOD, and CAT that scavenge the produced ROS. The imbalance between intracellular prooxidants and antioxidants leads to an increase in both DNA damage and peroxidation of membrane lipids (Czaja 2007). In our study, liver damage evidenced by changes in biochemical markers (AST, ALT, $\gamma \mathrm{GT}, \mathrm{LDH}$ and albumin) and tissue pathology of the liver in CsA-treated group was associated with increased oxidative stress. CsA treated rats showed a significant elevation in hepatic TBARS and a decline in both enzymatic and non-enzymatic antioxidants, SOD, CAT, GPx and GSH, as compared to control concentrations. Oxidative damage has an important role in the pathogenesis of CsA induced- hepatotoxicity (El-Sokkary et al. 2005). Excess production of ROS by CsA is thought to be related to two important mechanisms, the first is due to its effect on mitochondria; CsA block the mitochondrial permeability transition pore (Nicolli et al. 1995) causing reduced calcium efflux which allows the mitochondria to accumulate large amounts of calcium (Fournier et al. 1987). These events affect the mitochondrial respiratory chain and cause uncoupling of oxidative phosphorylation (Salducci et al. 1992) with subsequent increase in ROS production. The second mechanism is through CsA metabolism by cytochrome P-450 3A that can also generate ROS (Serino et al 1994). Previous studies found that CsA treatment inhibits the expression and activity of antioxidant enzymes like SOD, CAT and GPx; and that exogenous antioxidants could inhibit the adverse actions of CsA (Lee 2010). To eliminate ROS from the cellular system, SOD and CAT function to remove superoxide radicals. GSH also plays an important role in the removal of ROS and protection of thiols in cell macromolecules. Depletion of glutathione has been associated with CsA hepatotoxicity (Duruibe et al. 1989). The antioxidant effects of glutathione are directly related to the key enzymes GPx and glutathione reductase that help protect cells from free radical generated toxicity (Ghadermarzi and Moosavi-Movahedi 1996). Reduced hepatic GSH might account for the inhibition of GPx activity. In addition, high levels of peroxides may explain the inhibition of CAT activity induced by CsA. The protective effect of vildagliptin in the present study may be partly explained by its ability to restore the prooxidant-antioxidant balance by 
enhancing hepatic radical-scavenging activities, increase the antioxidant defense and prevent the formation of free radicals originating from peroxidation products and from metabolism of CsA. Vildagliptin maintained hepatic enzymatic (SOD, CAT and GPx) and non-enzymatic antioxidants (GHS) in spite of CsA administration. Vidagliptin was found to ameliorate oxidative stress and pancreatic beta cell destruction in type 1 diabetic rats both by reducing levels of the stress marker, TBARS as well as by increasing activity of enzymatic antioxidants SOD and CAT (Ávila Dde et al. 2013).

As a DPP-4 inhibitor, vildagliptin hinders degradation of bioactive incretins, GLP-1 and GIP and amplifies their biological action. Vildagliptin treatment protects diabetic rats from the loss of renal vascular reactivity and the development of glomerulosclerosis perhaps secondary to a reduction in oxidative stress (Vavrinec et al. 2014). Liu et al. (2012) found that vildagliptin prevented the progression of diabetic nephropathy in rats by the enhancement of active GLP-1 level, which activated GLP-1R leading to antioxidative and antiapoptotic effects.

Proapoptotic Bcl2 family members, such as $t \mathrm{Bid}$, Bax and Bak, promote formation of specific cytochrome $c$ release channels in the mitochondrial outer membrane (Wei et al. 2001). Cytochrome $c$ released after mitochondrial swelling initiates caspase-dependent apoptotic signaling (Jiang and Wang 2004).

Because oxidative stress is a well known apoptosis mediator, many apoptosis inhibitors have an antioxidant activity or increase antioxidant defense mechanisms. By ameliorating oxidative stress induced by CsA, vildagliptin might have decreased CsA-induced apoptosis as evidenced by increased antiapoptotic protein $\mathrm{Bcl} 2$ and decreased that of proapoptotic protein Bax expression. Chronic administration of CsA in rats (2weeks, $15 \mathrm{mg} / \mathrm{kg} / \mathrm{day}$ ) causes increased number of apoptotic cells in liver tissues when counted using the TUNEL method (Goksu Erol et al. 2013). Shihab et al. (1999) proved that CsA-induced nephrotoxicity is associated with apoptosis caused by upregulation of the proapoptotic factors p53 and Bax and downregulation of the antiapoptotic factor $\mathrm{Bcl} 2$ in a rat chronic nephrotoxicity model. In pancreatic islets of diabetic mice vildagliptin treatment was found to inhibit apoptosis (Wu et al. 2015). Tarantino et al. (2011b) deduced that there is a certain balance between apoptosis and anti-apoptosis in determining the net effect on hepatocytes survival and hypothesized that serum Bcl2 levels reflect the steady state of this anti-apoptotic protein. Serum Bcl-2 increase is a likely response to the apoptotic process to improve survival of hepatocytes. If the response to the metabolic injury 
was good (increased serum levels of Bcl-2) probably the more severe form would not develop. Tarantino et al. (2011a) illustrated similar levels of cytochrome c and gammaglutamyl transferase in patients suffering from simple fatty liver or from the more severe nonalcoholic steato-hepatitis.

A similar effect of vildagliptin in reducing oxidative stress and apoptois was reported in cardiac ischemia/reperfusion injury (Apaijai et al. 2014). Also, Chinda et al. (2014) reported a similar effect of vildagliptin on oxidative stress and apoptosis and explained it by the ability of vildagliptin to attenuate cardiac mitochondrial dysfunction through reducing ROS level and mitochondrial swelling.

$\mathrm{NF}-\kappa \mathrm{B}$ is a nuclear transcription factor found in the cytoplasm of liver cells where it plays an essential role in the regulation of inflammatory signaling pathways (Luedde and Schwabe 2011). A heterodimeric complex of p65/RelA and p50 is the most common form of NF- $\kappa B$ in

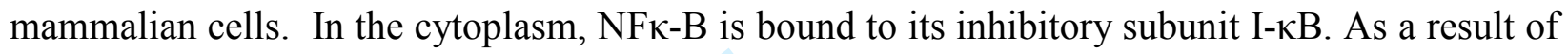
oxidative stress, NFKB is activated and phosphorylated from its inhibitory subunit and translocated to the nucleus of the hepatic cell where it binds to DNA. This causes upregulation of DNA transcription of many inflammatory genes like cytokines, chemokines and receptors of advanced glycation end products (Zhu and Fung 2000). In rat hepatocyte cultures, CsA induces transcriptional activation of NF-אB (Andrés et al. 2002). Assessment of hepatic nuclear extract in the current study showed significant increase NF- $\kappa$ B p65 DNA binding activity in CsA treated rats as compared to control. Viladagliptin on the other hand reduced hepatic NFK-B activity caused by CsA administration. Miyagawa et al. (2013) demonstrated the anti-inflammatory benefits of vildagliptin in diabetic mice. They reported slight improvement of hepatic steatosis with a significant reduction of plasma inflammatory markers (i.e. C-reactive protein, IL-6 and TNF- $\alpha$ levels) as compared to control and attributed these effects to activation of GLP- 1R on hepatocytes caused by enhanced levels of GLP-1 by vildagliptin.

To further elucidate the possible mechanism by which vildagliptin improve CsA-induced hepatotoxicity, DPP-4 level was estimated during CsA administration. The data showed that rats treated with CsA alone exhibited significant increase in DPP-4 level compared with untreated rats. On the other hand, vildagliptin concomitant with CsA administration significantly normalized DPP-4 levels. The liver is one of the organs that highly express DPP-4 (Mentzel et al. 1996). Hepatic DPP-4 is thought to be involved in the regulation of hepatic metabolism (Itou et 
al. 2013). Balaban et al. (2007) reported that serum DPP-4 activity and hepatic expression of DPP-4 are correlated with hepatic steatosis and non-alcoholic fatty liver disease grading. Nonalcoholic fatty liver disease is characterized by the accumulation of fat in the liver when it exceeds $5 \%-10 \%$ of its weight. In addition to leading to major histopathological alterations, it may be associated with elevated liver enzymes and abnormal liver function, ranging from steatosis to steatohepatitis, fibrosis, and cirrhosis (Tarantino and Finelli 2013). Moreover, DPP-4 deficient rats show lower levels of hepatic pro-inflammatory and pro-fibrotic cytokines and reduced hepatic steatosis compared to wild type rats (Balaban et al. 2007).

Also, Gaetaniello et al. (1998) reported that inhibition of DPP-4 in human hepatoma cells suppress tyrosine kinase, leading to anti-apoptotic effects.

Thus from the present study, the preventive effect of vildagliptin was attributed to DPP-4 inhibition that leads to anti-inflammatory and anti-apoptotic as evident by significant effect of vildagliptin on the altered activity and expression of $\mathrm{NF}-\kappa \mathrm{B}, \mathrm{Bax}$ and $\mathrm{Bcl} 2$, respectively.

In conclusion, the results of the present study demonstrate that administration of vildagliptin might have the potential to protect the liver against CsA toxic effects through reducing hepatic oxidative stress, apoptosis and inflammation.

Conflict of Interest: The authors declare that they have no conflict of interest Acknowledgement:

The authors acknowledge Dr. Hala Muhammed Ali Yosef, Assistant Professor of Pathology, Faculty of Medicine, Taibah University, El-Madinah El-Munawarah, Saudi Arabia for providing assistance.

No fund.

\section{References:}

Andrés, D., Díez-Fernández, C., Castrillo, A., and Cascales, M. 2002. Relationship between the activation of heat shock factor and the suppression of nuclear factor- $\kappa \mathrm{B}$ activity in rat hepatocyte cultures treated with cyclosporine A. Biochem. Pharmacol. 64 (2): 247-56. PMID: 12123745. 
Apaijai, N., Chinda, K., Palee, S., Chattipakorn, S., and Chattipakorn, N. 2014. Combined vildagliptin and metformin exert better cardioprotection than monotherapy against ischemiareperfusion injury in obese-insulin resistant rats. PLoS One, 9 (7): e102374. PMID: 25036861 .

Ávila Dde, L., Araújo, G.R., Silva, M., Miranda, P.H., Diniz, M.F., Pedrosa, M.L., et al. 2013. Vildagliptin ameliorates oxidative stress and pancreatic beta cell destruction in type 1 diabetic rats. Arch. Med. Res. 44 (3):194-202. PMID: 23523961.

Balaban, Y.H., Korkusuz, P., Simsek, H., Gokcan, H., Gedikoglu, G., Pinar, A., et al. 2007. Dipeptidyl peptidase IV (DDP IV) in NASH patients. Ann. Hepatol. 6 (4): 24250. PMID: 18007554.

Barnett, A. 2006. DPP-4 inhibitors and their potential role in the management of type-2 diabetes. Int. J. Clin. Pract. 60 (11):1454-70. PMID: 17073841.

Chinda, K., Sanit, J., Chattipakorn, S., and Chattipakorn, N. 2014. Dipeptidyl peptidase-4 inhibitor reduces infarct size and preserves cardiac function via mitochondrial protection in ischaemia-reperfusion rat heart. Diab. Vasc. Dis. Res. 11(2):75-83. PMID: 24357666.

Czaja, M.J. 2007. Cell signaling in oxidative stress-induced liver injury. Semin. Liver. Dis. 27 (4): 378-89. PMID: 17979074.

Das, S.S., Hayashi, H., Sato, T., Yamada, R., Hiratsuka, M., and Hirasawa, N. 2014. Regulation of dipeptidyl peptidase 4 production in adipocytes by glucose. Diabetes Metab. Syndr. Obes. 7:185-94. PMID: 24920931.

Duruibe, V.A., Okonmah, A., and Blyden, G.T. 1989. Effect of cyclosporin on rat liver and kidney glutathione content. Pharmacology, 39 (4): 205-12. PMID: 2608719.

El-Sokkary, G.H., Abdel-Rahman, G.H., and Kamel, E.S. 2005. Melatonin protects against lead-induced hepatic and renal toxicity in male rats. Toxicology, 213 (1-2): 25-33. PMID: 15964675.

Fournier, N., Ducet, G., and Crevat, A. 1987. Action of cyclosporine on mitochondrial calcium fluxes. J. Bioenerg. Biomembr. 19 (3): 297-303. PMID: 3114244.

Gaetaniello, L., Fiore, M., de Filippo, S., Pozzi, N., Tamasi, S., and Pignata, C. 1998. Occupancy of dipeptidyl peptidase IV activates an associated tyrosine kinase and triggers an 
apoptotic signal in human hepatocarcinoma cells. Hepatology, 27 (4): 934-42. PMID: 9537431.

Ghadermarzi, M., and Moosavi-Movahedi, A.A. 1996. Determination of the kinetic parameters for the "suicide substrate" inactivation of bovine liver catalase by hydrogen peroxide. J. Enzyme Inhib. 10 (3): 167-75. PMID: 8835942.

GoksuErol, A.Y., Avc1, G., Sevimli, A., Ulutas, E., and Ozdemir, M. 2013. The protective effects of omega 3 fatty acids and sesame oil against cyclosporine Ainduced nephrotoxicity. Drug Chem. Toxicol. 36 (2): 241-48. PMID: 22950701.

Gorrell, M.D., Gysbers, V., and McCaughan, G.W. 2001. CD26: a multifunctional integral membrane and secreted protein of activated lymphocytes. Scand. J. Immunol. 54 (3): 249-64. PMID: 11555388.

Itou, M., Kawaguchi, T., Taniguchi, E., and Sata, M. 2013. Dipeptidyl peptidase-4: a key player in chronic liver disease. World J. gastroenterol. 19 (15): 2298-306. PMID: 23613622.

Jiang, X., and Wang, X. 2004. Cytochrome C-mediated apoptosis. Annu. Rev. Biochem. 73:87-106. PMID: 15189137.

Josephine, A., Nithya, K., Amudha, G., Veena, C.K., Preetha, S.P., and Varalakshmi, P. 2008. Role of sulphated polysaccharides from Sargassum Wightii in Cyclosporine Ainduced oxidative liver injury in rats. BMC Pharmacol. 8:4. PMID: 18289374.

Kwak, C.S., and Mun, K.C. 2000. The beneficial effect of melatonin for cyclosporine hepatotoxicity in rats. Transplant Proc. 32 (7): 2009-10. PMID: 11120043.

Lee, J. 2010. Use of antioxidants to prevent cyclosporine a toxicity. Toxicol. Res. 26 (3): 163-70. PMID: 24278520.

Liu, W.J., Xie, S.H., Liu, Y.N., Kim, W., Jin, H.Y., Park, S.K., et al. 2012. Dipeptidyl peptidase IV inhibitor attenuates kidney injury in streptozotocin-induced diabetic rats. J. Pharmacol. Exp. Ther. 340 (2): 248-55. PMID: 22025647.

Luedde, T., and Schwabe, R.F. 2011. NF- $\kappa$ B in the liver-linking injury, fibrosis and hepatocellularcarcinoma. Nat. Rev. Gastroenterol. Hepatol. 8 (2): 108-18. PMID: 21293511. 
McCashland, T.M., Donovan, J.P., Amelsberg, A., Rossi, S.S., Hofmann, A.F., Shaw, B.W. Jr, and Quigley, E.M. 1994. Bile acid metabolism and biliary secretion in patients receiving orthotopic liver transplants: differing effects of cyclosporine and FK 506. Hepatology, 19 (6): 1381-9. PMID: 7514561.

Mentzel, S., Dijkman, H.B., Van Son, J.P., Koene, R.A., and Assmann, K.J. 1996. Organ distribution of aminopeptidase A and dipeptidyl peptidase IV in normal mice. J. Histochem. Cytochem. 44 (5): 445-61. PMID: 8627002.

Miyagawa, K., Kondo, T., Goto, R., Matsuyama, R., Ono, K., Kitano, S., et al. 2013. Effects of combination therapy with vildagliptin and valsartan in a mouse model of type 2 diabetes. Cardiovasc. Diabetol. 12: 160. PMID: 24188631.

Morán, D., De Buitrago, J.M., Fernández, E., Galán, A.I., Muñoz, M.E., and Jiménez, R. 1998. Inhibition of biliary glutathione secretion by cyclosporine A in the rat: possible mechanisms and role in the cholestasis induced by the drug. J. Hepatol. 29 (1):68-77. PMID: 9696494.

Nicolli, A., Basso, E., Petronilli, V., Wenger, R.M., and Bernard, P. 1995. Interactions of cyclophilin with the mitochondrial inner membrane and regulation of the permeability transition pore and cyclosporine A-sensitive channel. J. Biol. Chem. 271 (4): 2185-92. PMID: 8567677.

Rezzani, R. 2004. Cyclosporine A and adverse effects on organs: histochemical studies. Prog. Histochem. Cytochem. 39 (2): 85-128. PMID: 15354618.

Rezzani, R., Buffoli, B., Rodella, L., Stacchiotti, A., and Bianchi, R. 2005. Protective role of melatonin in cyclosporine A-induced oxidative stress in rat liver. Int. Immunopharmacol. 5 (9): 1397-1405. PMID: 15953566.

Rezzani, R., Rodella, L., and Bianchi, R. 2001. Melatonin antagonises the cyclosporine A immunosuppressive effects in rat thymuses. Int. Immunopharmacol. 1 (8): 1615-19. PMID: 11515824. 
Salducci, M.D., Chauvet-Monges, A.M., Berland, Y., Dussol, B., Elsen, R., and Crevat, A. 1992. The restoration of ATP synthesis may explain the protective effect of calcium antagonist against cyclosporine A nephrotoxicity. Life Sci. 50 (26): 2053- 58. PMID: 1318988.

Serino, F., Grevel, J., Napoli, K.L., Kahan, B.D., and Strobel, H.W. 1994. Oxygen radical formation by the cytochrome P450 system as a cellular mechanism for cyclosporine toxicity. Transplant. Proc. 26 (5): 2869-70. PMID: 7940922.

Shihab, F.S., Andoh, T.F., Tanner, A.M., Yi, H., and Bennett, W.M. 1999. Expression of apoptosis regulatory genes in chronic cyclosporine nephrotoxicity favors apoptosis. Kidney Int. 56 (6): 2147-59. PMID: 10594790.

Tarantino, G., Colao, A., Capone, D., Conca, P., Tarantino, M., and Grimaldi E. $2011 a$. Circulating levels of cytochrome $\mathrm{C}$, gammaglutamyl transferase, triglycerides and unconjuga ted bilirubin inoverweight/obese patients with non-alcoholic fatty liver disease. J. Biol. Regul. Homeost. Agents, 25(1):47-56.

Tarantino, G., and Finelli, C. 2013. What about non-alcoholic fatty liver disease as a new criterion to define metabolic syndrome? World J. Gastroenterol. 19 (22): 3375-3384.

Tarantino, G., Scopacasa, F., Colao, A., Capone, D., Tarantino, M., Grimaldi, E., et al. 2011b. Serum Bcl2 concentrations in overweightobese subjects with nonalcoholic fatty liver disease. World J. Gastroenterol. 17(48):5280-8.

Vavrinec, P., Henning, R.H., Landheer, S.W., Wang, Y., Deelman, L. E., van Dokkum, R.P., et al. 2014. Vildagliptin restores renal myogenic function and attenuates renal sclerosis independently of effects on blood glucose or proteinuria in Zucker Diabetic Fatty rat. Curr. Vasc. Pharmacol. 12 (6): 836-44. PMID: 24066937.

Wei, M.C., Zong, W.X., Cheng, E.H., Lindsten, T., Panoutsakopoulou, V., Ross, A.J., et al. 2001. Proapoptotic BAX and BAK: a requisite gateway to mitochondrial dysfunction and death. Science, 292(5517): 727-30. PMID: 11326099. 
Wixson, S.K., White, W.J., Hughes, H.C.Jr., Lang, C.M, and Marshall, W.K. 1987. A comparison of pentobarbital, fentanyl-droperidol, ketamine-xylazine and ketamine-diazepam anesthesia in adult male rats. Lab. Anim. Sci. 37 (6): 726-730. PMID: 3437748.

Wu, Y.J., Guo, X., Li, C.J., Li, D.Q., Zhang, J., Yang, Y., et al. 2015. Dipeptidyl peptidase-4 inhibitor, vildagliptin, inhibits pancreatic beta cell apoptosis in association with its effects suppressing endoplasmic reticulum stress in db/db mice. Metabolism, 64 (2):226-35. PMID: 25195070.

Zhu, W., and Fung, P.C. 2000. The roles played by crucial free radicals like lipid free radicals, nitric oxide, and enzymes NOS and NADPH in CCl4- induced acute liver injury of mice. Free Radic. Biol. Med. 29(9):870-80. PMID: 11063912. 
Table (1): Effect of vildagliptin administration on serum biological changes in CsA-induced hepatotoxicity in rats

\begin{tabular}{|c|c|c|c|c|}
\hline \hline & Control & Vildagliptin & CsA & CsA-vildagliptin \\
\hline \hline ALT(U/L) & $50.04 \pm 15.27$ & $49.07 \pm 14.17$ & $101.7 \pm 31.14^{\text {aaa }}$ & $63.7 \pm 18.24^{\text {bb }}$ \\
AST(U/L) & $145.75 \pm 41.75$ & $140.70 \pm 38.75$ & $254 \pm 73.26^{\text {aaa }}$ & $177 \pm 5.06^{\mathrm{b}}$ \\
$\boldsymbol{\gamma} \mathbf{G T}(\mathbf{U} / \mathbf{L})$ & $22.34 \pm 6.25$ & $24.27 \pm 6.99$ & $42.71 \pm 11.65^{\text {aaa }}$ & $28.76 \pm 8.23^{\mathrm{b}}$ \\
$\mathbf{L D H}(\mathbf{U} / \mathbf{L})$ & $667.70 \pm 19.12$ & $678.67 \pm 19.43$ & $1375.70 \pm 383.82^{\text {aaa }}$ & $785.7 \pm 225.43^{\mathrm{bbb}}$ \\
Albumin(g/d) & $4.77 \pm 1.27$ & $4.67 \pm 1.19$ & $2.68 \pm 0.76^{\text {aa }}$ & $4.41 \pm 1.1^{\mathrm{b}}$ \\
DPP-4 (ng/ml) & $34.05 \pm 10.32$ & $29.09 \pm 8.43$ & $109.06 \pm 33.66^{\text {aaa }}$ & $43.6 \pm 13.49^{\mathrm{bbb}}$ \\
\hline
\end{tabular}

ALT, alanine transaminase; $\overline{\mathrm{AST}}$, aspartate aminotransferase; $\overline{\gamma \mathrm{GT}}$, Gamma Glutamyl

Transferase; LDH, lactate dehydrogenase; DPP-4; dipeptidyl peptidase-4, CsA; cyclosporine.

Data are expressed as mean $\pm \mathrm{SD}, n=8$.

aa $p<0.01$, aaa $p<0.001$ statistically different from mean value of control group using one-way ANOVA test followed by Tukey-Kramer multiple comparison test

$\mathrm{b} p<0.05, \mathrm{bb} p<0.01, \mathrm{bbb} p<0.001$ statistically different from mean value of CsA-treated groups using one-way ANOVA test followed by Tukey-Kramer multiple comparison test 
Table (2): Effect of vidagliptin administration on hepatic oxidative markers changes in CsA-induced hepatotoxicity in rats

\begin{tabular}{|c|c|c|c|c|}
\hline \hline & Control & Vildagliptin & CsA & CsA-vildagliptin \\
\hline \hline TBARS (nM/g tissue) & $39.75 \pm 11.65$ & $41.25 \pm 12.36$ & $112.6 \pm 32.39^{\text {aaa }}$ & $57.75 \pm 17^{\mathrm{bbb}}$ \\
SOD (U/g tissue) & $21.87 \pm 5.71$ & $20.75 \pm 5.69$ & $9.75 \pm 2.77^{\text {aaa }}$ & $17.78 \pm 4.72^{\mathrm{b}}$ \\
CAT ( $\boldsymbol{M M} / \mathbf{m i n} / \mathbf{g}$ tissue) & $98.07 \pm 28.2$ & $95.79 \pm 27.46$ & $26.73 \pm 7.1^{\text {aaa }}$ & $75.76 \pm 21.6^{\mathrm{bb}}$ \\
GPx ( $\boldsymbol{\mu M} / \mathbf{m i n} / \mathbf{g}$ tissue) & $10.75 \pm 3.31$ & $11.07 \pm 3.48$ & $3.57 \pm 1.22^{\text {aaa }}$ & $8.79 \pm 2.57^{\mathrm{bb}}$ \\
GSH ( $\boldsymbol{\mu M} / \mathbf{g}$ tissue) & $2.67 \pm 0.76$ & $2.42 \pm 0.571$ & $0.75 \pm 0.23^{\text {aa }}$ & $2.02 \pm 0.62^{\mathrm{bb}}$ \\
\hline \hline
\end{tabular}

TBARS, thiobarbituric acid reactive substance; SOD, superoxide dismutase; GSH, glutathione; CAT, catalase; GPx; glutarhione peroxidase, CsA, cyclosporine.

Data are expressed as mean $\pm \mathrm{SD}, n=8$

aa $p<0.01$, aaa $p<0.001$ statistically different from mean value of control group using one-way ANOVA test followed by Tukey-Kramer multiple comparison test.

b $p<0.05$, bb $p<0.01$, bbb $p<0.001$ statistically different from mean value of CsA-treated groups using one-way ANOVA test followed by Tukey-Kramer multiple comparison test. 
Table 3: Effect of vildagliptin administration on hepatic nuclear extracts of NF- $\mathrm{kB}$ in CsAinduced hepatotoxicity in rats

\begin{tabular}{|c|c|}
\hline \hline & NF-KB activation (OD 450nm) \\
\hline \hline Control & $0.45 \pm 0.09$ \\
\hline Vildagliptin & $0.35 \pm 0.065$ \\
CsA & $2.01 \pm 0.65^{\text {aaa }}$ \\
\hline CsA-vilagliptin & $0.76 \pm 0.29^{\mathrm{bbb}}$ \\
\hline \hline
\end{tabular}

$\mathrm{NF}-\mathrm{kB}$; nuclear factor kappa B, CsA; cyclosporine

Values are represented as mean $\pm \mathrm{SD}, n=8$.

aaa $p<0.001$ statistically different from mean value of control group using one-way ANOVA test followed by Tukey-Kramer multiple comparison test.

bbb $p<0.001$ statistically different from mean value of CsA-treated groups using one-way ANOVA test followed by Tukey-Kramer multiple comparison test. 
Table (4): Effect of vidagliptin administration on hepatic protein level of Bax and Bcl2 in CsA-induced hepatotoxicity in rats

\section{CsA; cyclosporine}

\begin{tabular}{|l|c|c|}
\hline \hline & Bax ng/gm tissue & Bcl2 ng/gm tissue \\
\hline \hline Control & $2.05 \pm 0.45$ & $5.57 \pm 1.44$ \\
Vildagliptin & $1.95 \pm 0.57$ & $5.07 \pm 1.16$ \\
CsA & $8.07 \pm 2.18^{\mathrm{aaa}}$ & $2.97 \pm 0.71^{\text {aaa }}$ \\
& $3.09 \pm 1.19^{\mathrm{bbb}}$ & $4.5 \pm 0.99^{\mathrm{b}}$ \\
\hline
\end{tabular}

Values are represented as mean $\pm \mathrm{SD}, n=8$.

aaa $p<0.001$ statistically significant as compared to the control using one-way ANOVA test followed by Tukey-Kramer multiple comparison test.

b $p<0.05$, bbb $p<0.001$ statistically different from mean value of CsA-treated group using oneway ANOVA test followed by Tukey-Kramer multiple comparison test. 


\section{Figure Legend:}

Figure (1): Effect of vildagliptin on pathological changes in rat liver induced by cyclosporine (CsA) (H and E):
A) Control group (magnification $\times 100$ ), B) vildagliptin group (magnification $\times 100$ ), C) CsA group (magnification $\times 200$ ), D) CsA + vildagliptin (magnification $\times 200$ ). 


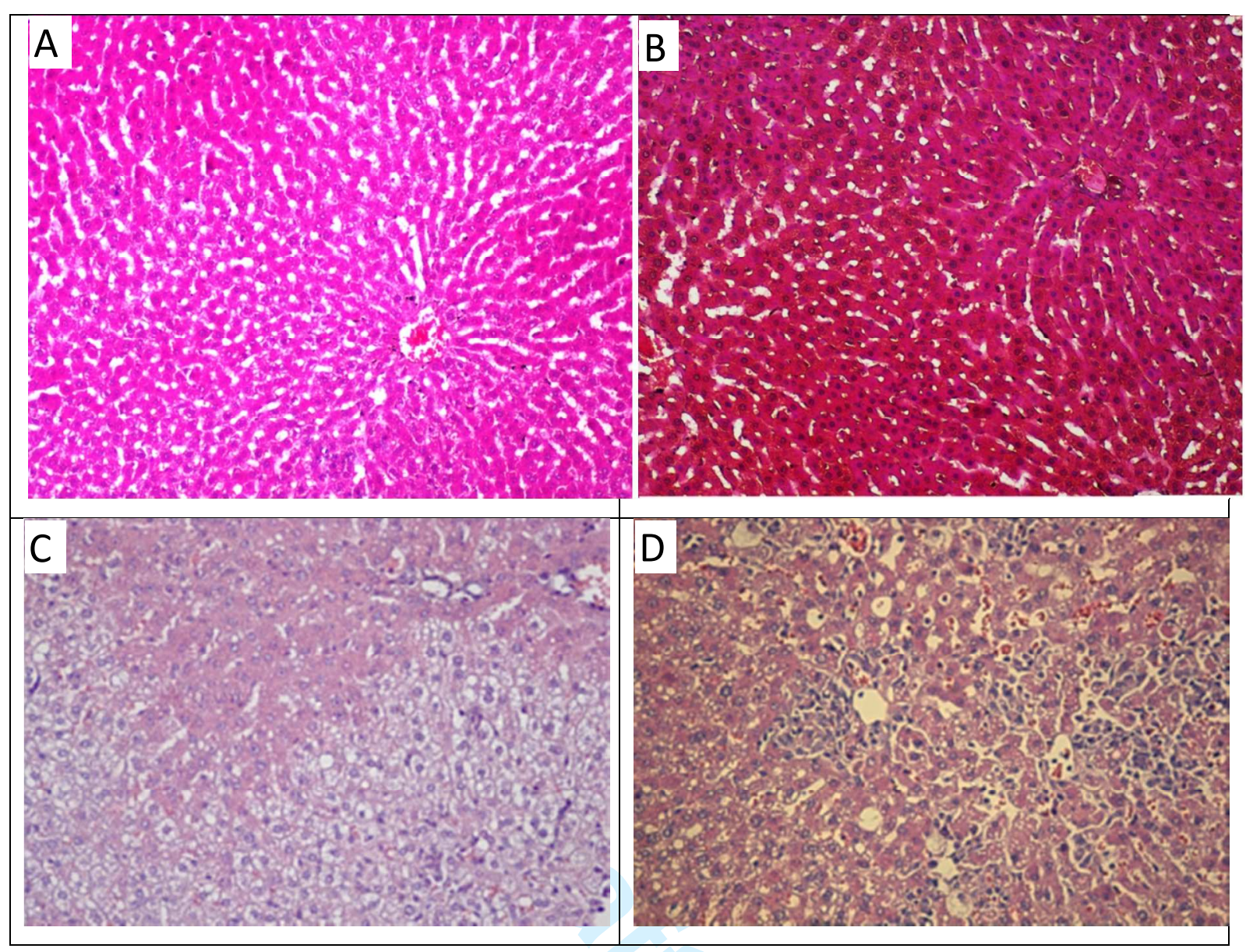

Figure 1 